\title{
Applying biomass and stem fluxes to quantify temporal and spatial fluctuations of an old-growth forest in disturbance
}

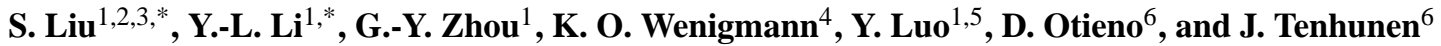 \\ ${ }^{1}$ South China Botanical Garden, Chinese Academy of Sciences, Guangzhou 510650, China \\ ${ }^{2}$ Agro-Environmental Protection Institute, Ministry of Agriculture, Tianjin 300191, China \\ ${ }^{3}$ Graduate School of the Chinese Academy of Sciences, Beijing 100039, China \\ ${ }^{4}$ Barr Engineering, Minneapolis, Minnesota, 55435, USA \\ ${ }^{5}$ Climatic and Agrometeorological Center of Guangdong Province, Guangzhou 510080, China \\ ${ }^{6}$ Department of Plant Ecology, University of Bayreuth, 95440 Bayreuth, Germany \\ *These authors contribute equally to this work.
}

Received: 28 December 2008 - Published in Biogeosciences Discuss.: 3 March 2009

Revised: 2 August 2009 - Accepted: 12 August 2009 - Published: 1 September 2009

\begin{abstract}
A subtropical old-growth forest was studied over a twelve-year period to investigate temporal and spatial fluctuations of biomass and stem fluxes under disturbances. Vegetations were categorized into three types according to disturbances caused by biotic and abiotic factors, including Castanopsis chinensis population, insect direct-influenced population, and insect indirect-influenced population according to disturbance scenarios. The biomass fluxes (growth and mortality) and stem fluxes (stem recruitment and mortality) were used to quantify population fluctuations. Annual average biomass growth rate was stable throughout the study while annual biomass mortality and stem fluxes increased consistently. C. chinensis population predominantly contributed to biomass fluxes of the community. Biomass and stem mortalities of insect direct-influenced population increased significantly during the whole study period (19922004). Results of indirect-influenced population showed that (1) the increase in biomass of the dominant species was well correlated between different intervals. Similar relationships were found in stem fluxes; (2) higher stem mortality occurred within the DBH range of 1 to $10 \mathrm{~cm}$; (3) stem fluxes in the canopy gaps were remarkably higher than those in closed canopy.
\end{abstract}

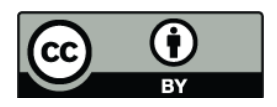

Correspondence to: G.-Y. Zhou (gyzhou@scbg.ac.cn)

\section{Introduction}

Community fluctuation is the shortest temporal division of the community dynamics; as it is a non-directional, quantitative change (Glenn-Lewin et al., 1992). Disturbance is a major cause of fluctuation (Chapin et al., 2002; Rydgren et al., 2004; Elderd and Doak, 2006) especially in old-growth forests (Tappeiner et al., 1997). An emerging challenge in ecosystem ecology is to improve our understanding of the properties and processes that allow forests to persist in the face of disturbance (Chapin et al., 2002). Research on forest fluctuation has mainly focused on pool dynamics, such as stem density, basal area or biomass. Pool dynamics are determined by the influx and efflux of material into and out of the forest ecosystem (Lewis et al., 2004). Thus, quantification of fluxes may be a better approach to better understand the fluctuation of forests under disturbance. In this study, we applied the concepts proposed by Lewis et al. (2004) to quantify the biomass and stem fluxes (Fig. 1). First, with regard to biomass, the forest was viewed as a simple system consisting of a biomass pool with its size changing as biomass was added to the pool by growth fluxes and subtracted from the pool by mortality fluxes (Lewis et al., 2004). Second, the same approach was also applied to stem: a pool of stems increased with stem recruitment (influx) and decreased with stem mortality (efflux; Lewis et al., 2004).

Stephenson and van Mantgem (2005) showed that in the absence of significant disturbance or environmental changes, mature communities experience less net change in biomass

Published by Copernicus Publications on behalf of the European Geosciences Union. 
through time (Lewis et al., 2004). There are few studies currently that have intensively analyzed biomass fluxes in mature communities subjected to disturbance. In this study, we report results from a study on an old-growth forest under disturbance. We examined how shifts in environmental conditions caused by disturbance impact on stem and biomass fluxes.

The study site was an old-growth forest in Dinghushan Man and Biosphere (MAB) Reserve. The forest was strongly affected by an insect (Thalassodes quadraria Guene) attack in the 1980's (Huang, 2000). The biomass and stem fluxes in a 1-ha plot of the old-growth forest were calculated over twelve years (divided into three periods: 19921994, 1994-1999 and 1999-2004) based on the concepts described above. The study addressed the following questions: (1) how do total biomass and stem fluxes of the old-growth forest change under disturbance? (2) Do these changes vary among species growing together in a forest community? (3) Are there any differences in the stem and biomass fluxes among DBH classes? (4) What role does canopy gaps play in biomass recruitment/mortality and stem fluxes?

\section{Methods}

\subsection{Forest monitoring plot}

The study site was a long-term monitoring plot located in the Dinghushan Man and Biosphere (MAB) Reserve $\left(23^{\circ} 09^{\prime} 21^{\prime \prime} \mathrm{N}-23^{\circ} 11^{\prime} 30^{\prime \prime} \mathrm{N}, 112^{\circ} 30^{\prime} 39^{\prime \prime} \mathrm{E}-112^{\circ} 33^{\prime} 41^{\prime \prime} \mathrm{E}\right)$ in Guangdong Province, China. The Reserve covers an area of 1155 ha and experiences a subtropical monsoon climate. The Reserve was established in 1950 to protect the only remnant of undisturbed natural monsoon evergreen broadleaf forest in the subtropics, and was accepted as the first MAB reserve in China in 1978. It has 2054 recorded native species of higher plants. The annual mean precipitation is $1678 \mathrm{~mm}$, mainly occurring from April to September. The annual mean relative humidity is 78 percent and the annual mean temperature is $22.3^{\circ} \mathrm{C}$. Elevation in the Reserve ranges from about 14 to $1000 \mathrm{~m}$ a.s.l. The bedrock is typically sandstone and shale (Zhou et al., 2006).

The forest at this site is intact and has not been disturbed by humans for more than 400 years (Zhou et al., 2006). The aboveground community can be divided into five layers: three arbor layers, one shrub layer, and one grass layer. In addition, the aboveground community has many kinds of interlayer plants (liana and epiphytes). The upper canopy is dominated by species with high importance values consisting of only a few individuals. Evergreen plants are predominant and are most often natives of the tropics and subtropics, such as Castanopsis chinensis, Canarium pimela, Schima superba, and Engelhardtia roxburghiana. The subcanopy layer is mainly composed of Cryptocarya concinna and Machilus chinensis (Zhou et al., 2006).

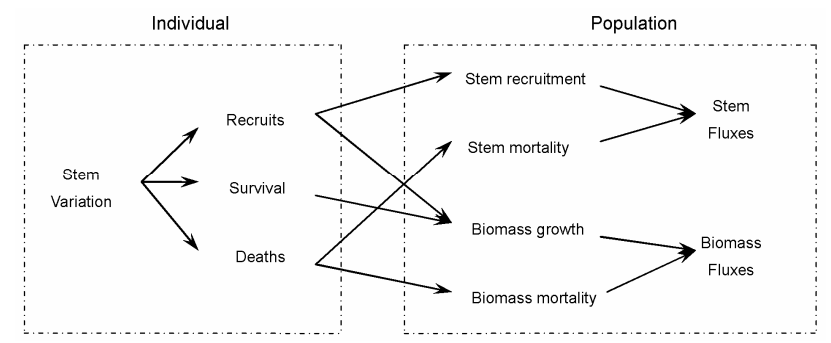

Fig. 1. Diagram for calculating stem and biomass fluxes.

The long-term monitoring plot was located in the core area of the Reserve. It was not easy to find another similar plot in core area, which has been protected for approximately 400 years. The monitoring plot was established in 1982 with an area of 0.2-ha, and was expanded to 1-ha in 1992.The plot was divided into 400 contiguous $5 \times 5 \mathrm{~m}$ sub-plots to study the biomass and stem fluxes of different forest gaps. Numbered permanent stakes were placed at the corners of each sub-plot (Fig. 2). In 1992, all trees $\geq 1 \mathrm{~cm}$ diameter at breast height (DBH) were tagged, measured, mapped and identified to a species level (a total of 107 species). The plot was revisited to record deaths, add and tag recruits that attained a DBH of $1 \mathrm{~cm}$ and renew measurements of DBH of survivals in 1994, 1999 and 2004.

According to the study of Guan et al. (2004), the long-term monitoring plot of the monsoon climate old-growth forest from 1981 to 2001 was mainly affected by two climate factors, typhoons and rainstorms. No other obvious differences were observed for other climate factors. Little fluctuation of the microclimate in the 400-yr-old monsoon evergreen forest was found based on review of the precipitation and temperature data for the study period.

\subsection{Disturbance and gap formation in the plot}

A serious insect disturbance (biotic factor) caused by Thalassodes quadraria Guene occurred from 1985 to 2006 in the plot, and significantly influenced the following four species of Lauraceae: Cryptocarya chinensis, Cryptocarya concinna, Machilus chinensis and Lindera chunii). These four species have been named as insect direct-influenced populations (Huang et al., 1998; Huang, 2000; Peng et al., 2003; Guan et al., 2004; Shi et al., 2005; Zhou et al., 2005; Peng ,2006; Zhang, 2006). This insect disturbance brought intense fluctuation to the community (Peng, 2006). On the basis of long-term (1983-1990) monitoring, Huang (2000) found that there was a positive feedback relationship between the population dynamics of T. quadraria and the population dynamics of the insect-influenced population. As a feedback, the population dynamics of this insect species caused the structure changes of the plant community (Huang, 2000).

In addition, three forest gaps occurred in the canopy (abiotic factor) in the plot occasioned by (1) tree-fall when two 


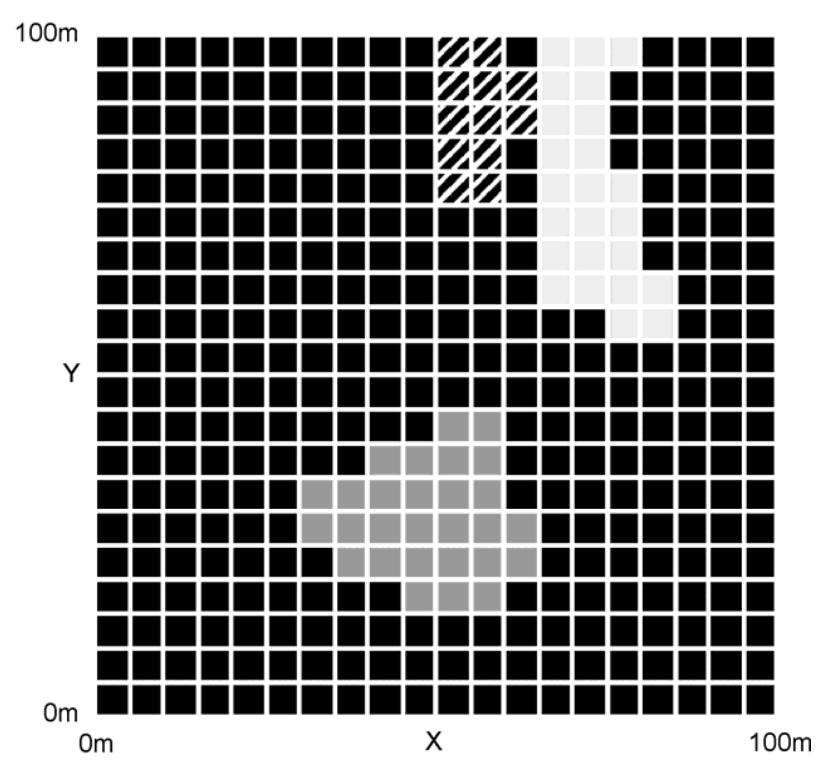

Fig. 2. Subplots in the 1-ha long-term monitoring plot in Dinghushan Man and Biosphere Reserve, Guangdong Province, China. Each subplot is $5 \mathrm{~m} \times 5 \mathrm{~m}$. Dark area, dark gray area, light gray area and hatched area refer to closed canopy, Gap 1 (tree fall gap), Gap 2 (landslide prior to 1992) and Gap 3 (2002 landslide), respectively.

canopy trees of $C$. chinensisi, the only species that composes the top canopy, fell during 1997-1998 (Gap 1; Fig. 2). When the two trees fell, they caused successive death of adjacent trees leading to an expanded forest gap (Liang, 2001). (2) Landslides occurring at two consecutive times, one prior to 1992 and the other in in 2002, leading to canopy Gap 2 and canopy Gap 3, respectively (Fig. 2).

\subsection{Dataset and calculations}

Biomass flux for each tree in the four inventories was estimated using regression models proposed by Wen et al. (1997). The sample trees were selected based on species composition and distribution of DBH classes in the monitoring plot. Using harvesting technique, sample trees were harvested and separated into trunk, branch, leaves and roots. Samples were oven dried at $80^{\circ} \mathrm{C}$ for $48 \mathrm{~h}$ and biomass determined. Taking the $\mathrm{DBH}$ as the predictive variable, the regression models were built on the basis of the differences of $\mathrm{DBH}$ classes. The four regression models were estimated by $\mathrm{DBH}$ classes of the plot: $\mathrm{DBH} \leq 5 \mathrm{~cm}, 5<\mathrm{DBH} \leq 10 \mathrm{~cm}$, $10<\mathrm{DBH} \leq 20 \mathrm{~cm}$ and $\mathrm{DBH}>20 \mathrm{~cm}$ (Wen et al., 1997). In order to maintain natural conditions in the long-term monitoring 1-ha plot, sample trees were harvested from areas with similar forest characteristics within a range of $100 \mathrm{~m}$ outside the established study plot.
Biomass of each tree in the plot in 1992, 1994, 1999 and 2004 were estimated using the regression models. Biomass pool in each year was calculated by summing the total biomass of each tree. Similarly, stem pool in each year was calculated by summing the total number of trees.

Each tree was marked as recruitment, survival or death over each period (1992-1994, 1994-1999 and 1999-2004; hereafter referred to as interval I, II and III), when measurements were carried out. Based on the marker, the stem variation of recruits and deaths in the plot amounted to stem recruitment and stem mortality, respectively (Fig. 1).

The change in biomass over each period was calculated based on the marker. If the marker signified a recruit or survival, this amounted to biomass growth. On the other hand, if the marker denoted death, this amounted to biomass decrease (Fig. 1).

Because the stem mortality and recruitment in interval I was small; the stem recruitment, stem mortality and biomass mortality of indirect-influenced populations were not calculated during this interval.

\subsection{Pool and fluxes classification}

The pool and fluxes of the plot were calculated to study the fluxes at community scale. In order to analyze the fluxes of different population groups, the pool and fluxes were divided into three populations groups. 107 species in the plot were classified according to disturbance scenarios: (1) C. chinensis population was the only one that composed the top portion of the canopy and was rarely affected by insect disturbance; (2) insect direct-influenced populations which included four species; (3) indirect-influenced populations which included all the other species.

Indirect-influenced populations were then classified into different pools according to dominant populations, $\mathrm{DBH}$ classes and subplots, respectively. Three kinds of classifications were used to study the response of indirect-influenced populations on disturbance. 25 populations were selected based on the population flux/community flux $\geq 1 \%$ in order to analyze the flux dynamics of dominant populations (Table 1).

\section{Results}

\subsection{Fluxes at the community scale}

Biomass and stem pools of the community increased continuously in the first two intervals and decreased in interval III (Table 2). In 1992-2004, the biomass and stem pools decreased by $27.4 \mathrm{Mg} \mathrm{ha}^{-1}$ and $662 \mathrm{Number} \mathrm{ha}^{-1}\left(\mathrm{~N} \mathrm{ha}^{-1}\right)$, respectively.

Minimal variation in annual biomass growth was experienced during the three periods; the average was $7.4 \pm 0.9 \mathrm{Mg} \mathrm{ha}^{-1} \mathrm{a}^{-1}$. Whereas annual biomass mortality increased over the three intervals, $0.2 \mathrm{Mgha}^{-1} \mathrm{a}^{-1}$, 
Table 1. Castanopsis chinensis population, insect direct-influenced populations and dominant populations of indirect-influenced populations. DBH is the average of 1992, 1994, 1999 and 2004 and the standard deviation is also provided. A code is only provided for the dominant populations among the indirect-influenced populations. The code correlates to the population code used in Fig. 6.

\begin{tabular}{|c|c|c|c|}
\hline Populations & Family & $\mathrm{DBH}$ & Code \\
\hline Castanopsis chinensisi & Fagaceae & $76.4 \pm 1.5$ & - \\
\hline Machilus chinensis & Lauraceae & $18.0 \pm 1.4$ & - \\
\hline Cryptocarya chinensis & Lauraceae & $13.5 \pm 0.5$ & - \\
\hline Cryptocarya concinna & Lauraceae & $9.5 \pm 3.7$ & - \\
\hline Lindera chunii & Lauraceae & $4.1 \pm 0.0$ & - \\
\hline Engelhardia roxburghiana & Juglandaceae & $34.3 \pm 2.3$ & I01 \\
\hline Schima superba & Theaceae & $32.8 \pm 1.8$ & I02 \\
\hline Pygeum topengii & Rosaceae & $18.9 \pm 1.9$ & I03 \\
\hline Gironniera subaequalis & Ulmaceae & $10.9 \pm 1.1$ & I04 \\
\hline Caryota ochlandra & Palmae & $9.5 \pm 0.6$ & I05 \\
\hline Acmena acuminatissima & Myrtaceae & $9.3 \pm 0.3$ & I06 \\
\hline Canarium album & Burseraceae & $7.0 \pm 1.2$ & I07 \\
\hline Meliosma rigida & Sabiaceae & $6.7 \pm 1.0$ & I08 \\
\hline Pterospermum acerifolium & Sterculiaceae & $6.6 \pm 0.5$ & I09 \\
\hline Mallotus paniculatus & Euphorbiaceae & $5.5 \pm 1.6$ & $\mathrm{I} 10$ \\
\hline Sarcosperma laurinum & Sapotaceae & $5.0 \pm 0.6$ & I11 \\
\hline Syzygium rehderianum & Myrtaceae & $4.9 \pm 0.6$ & $\mathrm{I} 12$ \\
\hline Aporusa yunnanensis & Euphorbiaceae & $4.8 \pm 0.3$ & $\mathrm{I} 13$ \\
\hline Schefflera octophylla & Araliaceae & $4.8 \pm 0.2$ & I14 \\
\hline Ficus esquiroliana & Moraceae & $4.6 \pm 0.6$ & $\mathrm{I} 15$ \\
\hline Xanthophyllum hainanense & Polygalaceae & $4.6 \pm 0.3$ & I16 \\
\hline Mallotus apelta & Euphorbiaceae & $3.6 \pm 0.7$ & I17 \\
\hline Macaranga sampsonii & Euphorbiaceae & $3.6 \pm 1.1$ & I18 \\
\hline Ardisia quinquegona & Myrsinaceae & $2.7 \pm 0.2$ & I19 \\
\hline Mischocarpus pentapetalus & Sapindaceae & $2.6 \pm 0.5$ & $\mathrm{I} 20$ \\
\hline Psychotria rubra & Rubiaceae & $2.4 \pm 0.2$ & $\mathrm{I} 21$ \\
\hline Ormosia glaberrima & Leguminosae & $2.4 \pm 0.3$ & $\mathrm{I} 22$ \\
\hline Aidia canthioides & Rubiaceae & $2.4 \pm 0.2$ & $\mathrm{I} 23$ \\
\hline Blastus cochinchinensis & Melastomataceae & $1.7 \pm 0.0$ & $\mathrm{I} 24$ \\
\hline Evodia lepta & Rutaceae & $1.7 \pm 0.4$ & $\mathrm{I} 25$ \\
\hline
\end{tabular}

Table 2. Fluctuations of biomass and stem pools of the community, the area of subplot was $5 \times 5 \mathrm{~m}^{2}$.

\begin{tabular}{rrr}
\hline Year & $\begin{array}{r}\text { Biomass } \\
\left(\mathrm{Mg} \mathrm{ha}^{-1}\right)\end{array}$ & $\begin{array}{r}\text { Stem } \\
\left(\mathrm{N} \mathrm{ha}^{-1}\right)\end{array}$ \\
\hline 1992 & 317.8 & 4338 \\
1994 & 332.7 & 4343 \\
1999 & 349.1 & 4465 \\
2004 & 290.4 & 3676 \\
\hline
\end{tabular}

4.8 $\mathrm{Mg} \mathrm{ha}^{-1} \mathrm{a}^{-1}$ and 18.1 $\mathrm{Mg} \mathrm{ha}^{-1} \mathrm{a}^{-1}$, respectively (Fig. 3). The biomass growth and mortality in 1992-2004 were 87.6 $\mathrm{Mg} \mathrm{ha}^{-1}$ and $114.9 \mathrm{Mg} \mathrm{ha}^{-1}$, respectively. As for stem fluxes, annual stem recruitments in the three intervals were $3.5 \mathrm{Nha}^{-1} \mathrm{a}^{-1}, 123.4 \mathrm{Nha}^{-1} \mathrm{a}^{-1}$ and $251.8 \mathrm{Nha}^{-1} \mathrm{a}^{-1}$ and
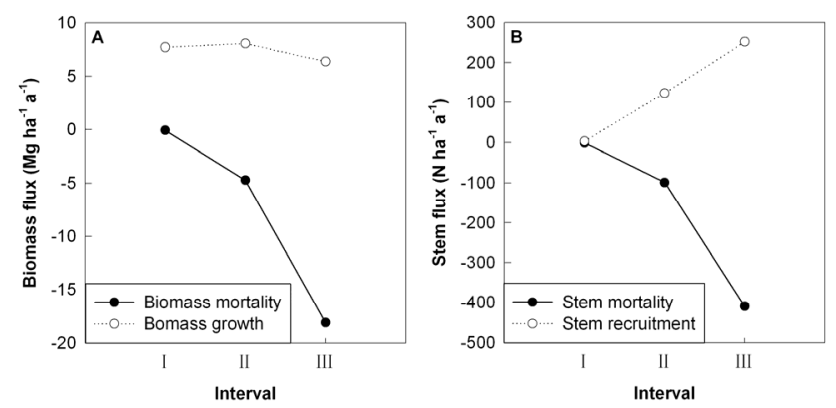

Fig. 3. Biomass fluxes (A) and stem fluxes (B) of the community.

annual stem mortality were $1.0 \mathrm{~N} \mathrm{ha}^{-1} \mathrm{a}^{-1}, 99.0 \mathrm{~N} \mathrm{ha}^{-1} \mathrm{a}^{-1}$ and $409.6 \mathrm{~N} \mathrm{ha}^{-1} \mathrm{a}^{-1}$. Stem fluxes expanded in the three periods. The stem recruitment and mortality in the whole census period amounted to $1883 \mathrm{Nha}^{-1}$ and $2545 \mathrm{Nha}^{-1}$, respectively. From 1992 to 1999, both annual biomass growth and annual stem recruitment were higher than biomass mortality and stem mortality, therefore both biomass and stem pools had increased. However, the biomass mortality and stem mortality had remarkably exceeded biomass growth and stem recruitment in interval III, which led to significant decreases in the pools.

\subsection{Fluxes of Castanopsis chinensisi population and in- sect direct-influence populations}

The annual biomass growth of $C$. chinensisi population accounted for $24.5 \%, 46.6 \%$ and $35.1 \%$ of the total biomass growth of the community in the three periods, respectively (Fig. 4). Its annual biomass mortality also accounted for $46.0 \%$ and $32.6 \%$ of the total biomass mortality of the community in interval II and interval III. The results suggest that the $C$. chinensisi population contributed significantly to the stability of biomass fluxes. There were only 15 individuals in 1992, 15 in 1994, 14 in 1999 and 12 in 2004.

Annual biomass mortality of insect direct-influenced populations was $30.1 \%$ in interval II and increased to $61.7 \%$ in interval III of the total biomass mortality of the community (Fig. 4). With the increase of annual biomass mortality, the annual biomass growth had reduced from $1.3 \mathrm{Mg} \mathrm{ha}^{-1} \mathrm{a}^{-1}$ in interval $\mathrm{I}$, to $0.9 \mathrm{Mgha}^{-1} \mathrm{a}^{-1}$ in interval II and to 0.4 $\mathrm{Mg} \mathrm{ha}^{-1} \mathrm{a}^{-1}$ in interval III. Meanwhile, the annual stem mortality of insect direct-influenced populations had increased to $22.0 \%$ in interval II and $25.8 \%$ in interval III of the total stem mortality among the community. The annual stem recruitment decreased with the increase of stem mortality. Thus, the annual biomass and stem fluxes of insect direct-influenced populations indicated an aggravation of insect disturbance in the period. 

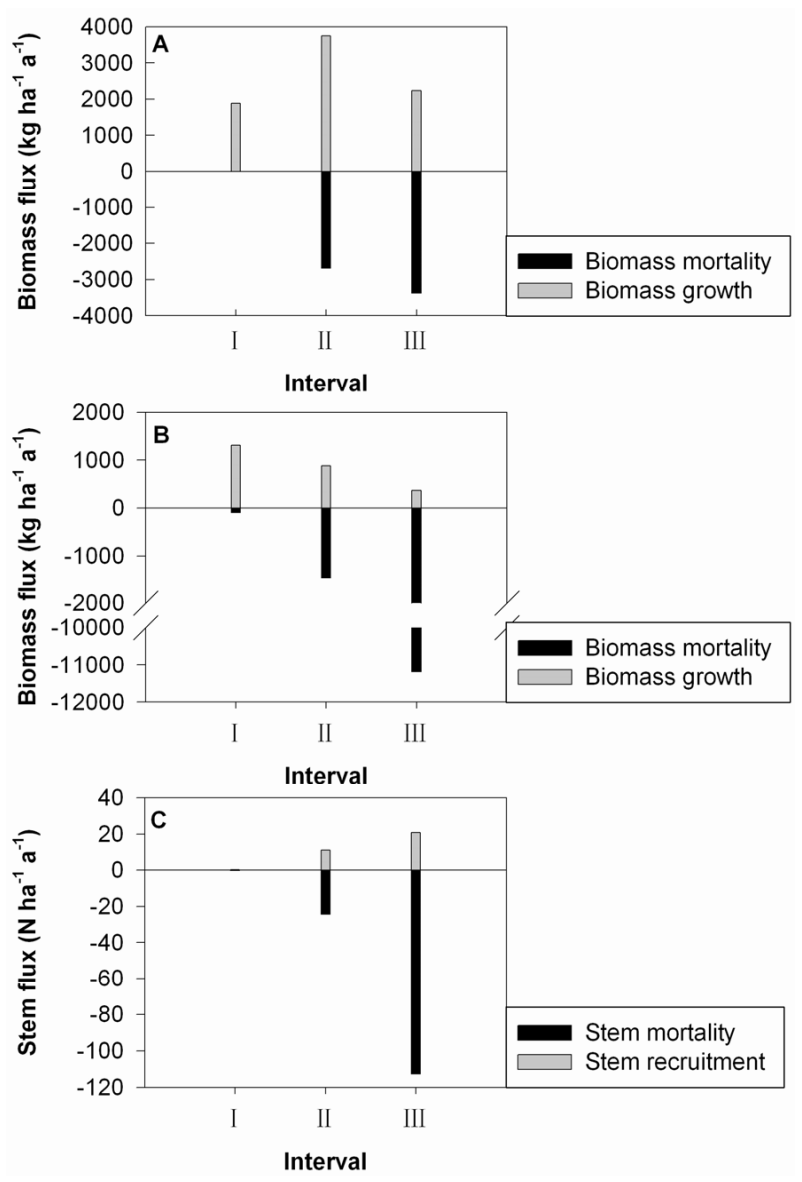

Fig. 4. (A) Biomass fluxes of Castanopsis chinensisi population, (B) biomass fluxes of insect direct-influenced populations and (C) stem fluxes of insect direct-influenced populations.

\subsection{Fluxes of indirect-influence populations}

The biomass and stem fluxes of indirect-influenced populations had similar dynamics in the community except that the differences between biomass growth and mortality were positive in all three periods (Fig. 5). Biomass growth in the three periods (I, II, III) was $4.5 \mathrm{Mg} \mathrm{ha}^{-1} \mathrm{a}^{-1}, 3.4 \mathrm{Mg} \mathrm{ha}^{-1} \mathrm{a}^{-1}$ and $3.8 \mathrm{Mg} \mathrm{ha}^{-1} \mathrm{a}^{-1}$, while the biomass mortality was $0 \mathrm{Mgha}^{-1} \mathrm{a}^{-1}, 0.6 \mathrm{Mgha}^{-1} \mathrm{a}^{-1}$ and $3.5 \mathrm{Mgha}^{-1} \mathrm{a}^{-1}$, respectively. The biomass pools of indirect-influenced populations rose in 1992-2004.

\subsubsection{Fluxes of dominant populations}

The dominant contributors to stem fluxes in the populations were primarily composed of average DBH classes $<10 \mathrm{~cm}$, while contributions to the biomass fluxes were spread across the DBH classes $(1.7 \pm 0.4 \mathrm{~cm}$ to $34.3 \pm 2.3 \mathrm{~cm})$.

Differences between the dominant populations in their annual biomass and stem fluxes were remarkable (Fig. 6). For biomass fluxes, the annual biomass growth varied
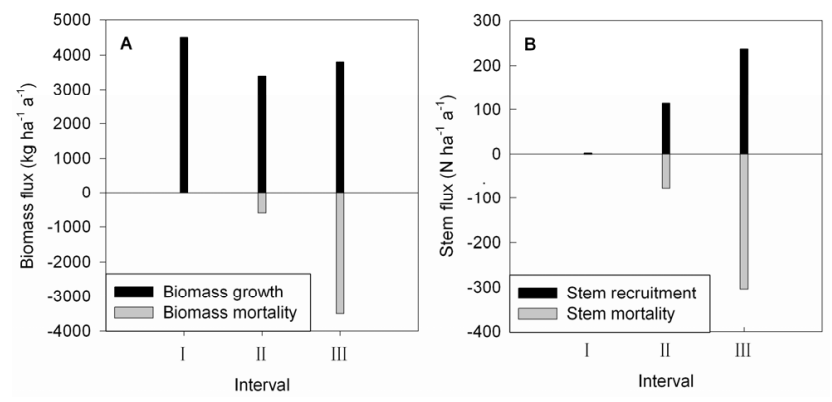

Fig. 5. Biomass and stem fluxes of indirect-influenced populations as indicated by (A) biomass fluxes and (B) stem fluxes.
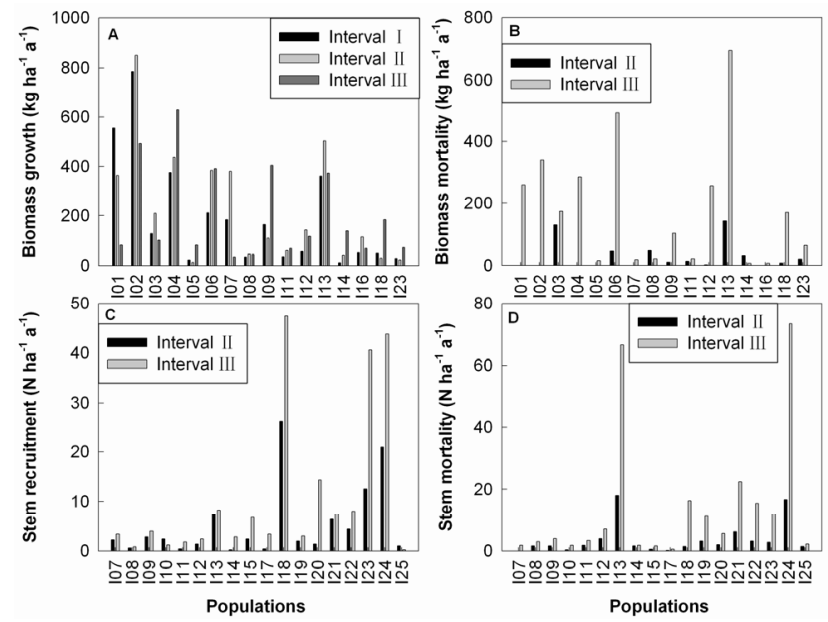

Fig. 6. Biomass and stem fluxes of each dominant population as indicated by (A) biomass growth, (B) biomass mortality, (C) stem recruitment and (D) stem mortality.

from 11.5 to $785.0 \mathrm{~kg} \mathrm{ha}^{-1} \mathrm{a}^{-1}$ in interval $\mathrm{I}$, from 13.6 to $850.1 \mathrm{~kg} \mathrm{ha}^{-1} \mathrm{a}^{-1}$ in interval II and from 34.6 to $628.9 \mathrm{~kg} \mathrm{ha}^{-1} \mathrm{a}^{-1}$ in interval III. The annual biomass mortality ranged from 0 to $142.4 \mathrm{~kg} \mathrm{ha}^{-1} \mathrm{a}^{-1}$ in interval II and 7.2 to $695.4 \mathrm{~kg} \mathrm{ha}^{-1} \mathrm{a}^{-1}$ in interval III. With the clear differences in biomass fluxes between dominant populations, the significance level of annual biomass growth between interval I and interval II and between interval II and interval III were both found at the 0.01 level (Pearson's correlation coefficients of 0.919 and 0.640 , respectively). No correlation of annual biomass mortality between interval II and interval III was found $(P=0.497)$.

The annual stem recruitment varied from 0.2 to $26.2 \mathrm{~N} \mathrm{ha}^{-1} \mathrm{a}^{-1}$ in interval II and from 0.2 to $47.4 \mathrm{Nha}^{-1} \mathrm{a}^{-1}$ in interval III. The significant correlation of stem recruitment between interval II and interval III was found at the 0.01 level $(P=0.936)$. Simultaneously, a similar relationship of stem mortality was also found at 0.01 level for stem recruitment between interval II and interval III $(P=0.978)$. 

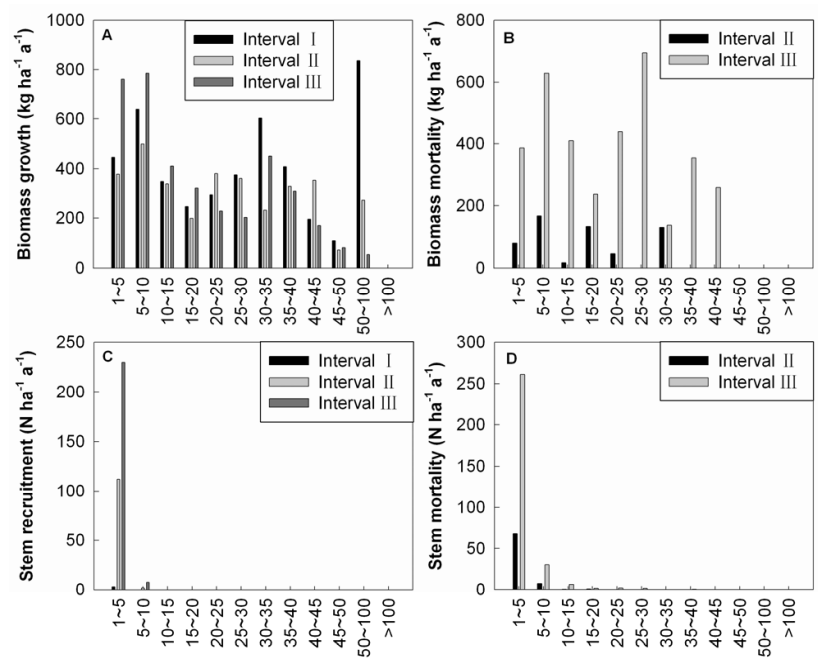

DBH classes

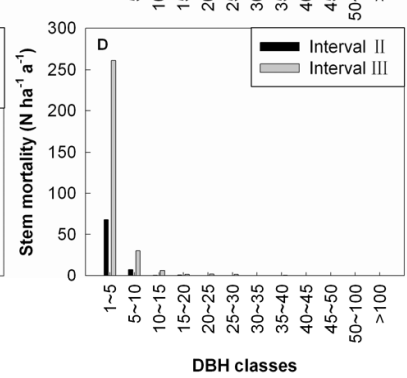

Fig. 7. Biomass and stem fluxes of each DBH class $(\mathrm{cm})$ as indicated by (A) biomass growth, (B) biomass mortality, (C) stem recruitment and (D) stem mortality.

\subsubsection{Fluxes of DBH classes}

Annual stem mortality decreased with the increase of DBH class (Fig. 7). The annual stem mortality in the DBH classes of $1-10 \mathrm{~cm}$ accounted for $97.9 \%$ in interval II and $96.0 \%$ in interval III of the total stem mortality of the community. Furthermore, the stem mortality and recruitment of each DBH class had both risen in the two periods.

The biomass mortality did not show a similar trend to stem mortality. The proportion of annual biomass mortality in 1$10 \mathrm{~cm}$ DBH class only accounted to $43.2 \%$ in interval II and $28.6 \%$ in interval III of the total biomass mortality of the community, suggesting that biomass mortality was not significantly influenced by stem mortality. There were no remarkable dynamics of annual biomass growth in the periods. The maximum annual biomass growth were found in different DBH classes for the three periods; $50-100 \mathrm{~cm}$ during interval I and $5-10 \mathrm{~cm}$ both during interval II and III.

\subsubsection{Fluxes of subplots}

The average stem mortality of each subplot was $1.0 \pm 1.4 \mathrm{~N}$ in interval II and $3.8 \pm 3.4 \mathrm{~N}$ in interval III, with maximum of $11 \mathrm{~N}$ and $25 \mathrm{~N}$, respectively. The average of stem recruitment was $1.4 \pm 2.5 \mathrm{~N}$ in interval II and $3.0 \pm 3.5 \mathrm{~N}$ in interval III, both with a maximum of $23 \mathrm{~N}$.

There were significant variances between the subplots in gaps and the subplots in closed canopy in both stem mortality and recruitment in interval II (Fig. 8; tested by ANOVA, $p<0.001)$. The significant variances were also found in interval III (tested by ANOVA, $p<0.001$ ).

The subplots in the different gaps showed different stem fluxes dynamics (Table 3). Firstly, the stem fluxes of subplots
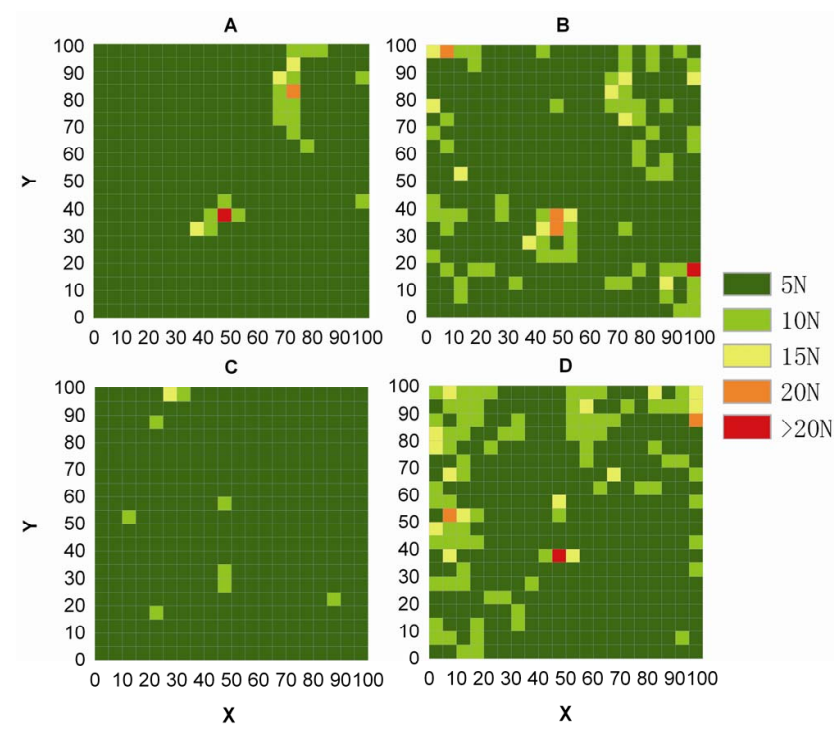

Fig. 8. Filled contour maps of stem fluxes (N) for each subplot as indicated by (A) stem recruitment in interval II, (B) stem recruitment in interval III, (C) stem mortality in interval II and (D) stem mortality in interval III.

in Gap 1 in two of the periods (II, III) were both significantly higher than the subplots in the closed canopy. Secondly, in Gap 2, the stem recruitment in interval II was highest, while the stem morality was the lowest. In interval III, the stem fluxes of Gap 2 had the similar variation with Gap 1. Thirdly, the stem mortality of Gap 3 significantly increased in interval III, which resulted from the influence of landslide.

The average annual biomass mortality of each subplot was $3.6 \pm 28.0 \mathrm{~kg} \mathrm{a}^{-1}$ in interval II and $22.2 \pm 64.2 \mathrm{~kg} \mathrm{a}^{-1}$ in interval III, respectively. The average annual biomass growth in the three intervals was $11.2 \pm 29.0 \mathrm{~kg} \mathrm{a}^{-1}, 8.5 \pm 18.4 \mathrm{~kg} \mathrm{a}^{-1}$ and $9.4 \pm 15.6 \mathrm{~kg} \mathrm{a}^{-1}$.

The variance of biomass fluxes between the subplots in gaps and the subplots in closed canopy was only found in interval II (tested by ANOVA, $p=0.027$, Fig. 9).

Compared to the annual biomass growth of Gap 1 in interval I, the annual biomass growth of Gap 1 decreased due to the influence of tree-fall in interval II, while it rapidly increased in interval III (Table 4). The biomass mortality of subplots in Gap 1 was higher than the subplots in closed canopy in both periods. As for Gap 2, the biomass growth of the subplots was always smaller than the subplots in the closed canopy in the three periods, but kept increasing, especially in interval III. The biomass mortality of Gap 2 also increased in interval II and interval III, at higher rates than the growth in biomass. Both the biomass growth and mortality of subplots in Gap 3 were affected by the occurrence of the landslide in interval III. 
Table 3. Stem fluxes of subplots $\left(5 \times 5 \mathrm{~m}^{2}\right.$ for each one $)$ in canopy gaps and closed canopy for intervals II and III.

\begin{tabular}{lrrrrr}
\hline \multirow{2}{*}{ Position } & Subplot & \multicolumn{2}{c}{ Stem recruitment (N) } & \multicolumn{2}{c}{ Stem mortality (N) } \\
\cline { 3 - 6 } & Number & Interval II & Interval III & Interval II & Interval III \\
\hline Subplot in Gap 1 & 28 & $3.3 \pm 5.0$ & $5.9 \pm 5.3$ & $2.1 \pm 1.7$ & $4.3 \pm 5.1$ \\
Subplot in Gap 2 & 24 & $6.2 \pm 4.5$ & $5.8 \pm 3.8$ & $0.3 \pm 0.8$ & $4.1 \pm 3.1$ \\
Subplot in Gap 3 & 12 & $0.3 \pm 0.7$ & $0.3 \pm 0.7$ & $1.0 \pm 0.7$ & $7.8 \pm 2.6$ \\
Subplot in closed canopy & 336 & $1.0 \pm 1.4$ & $2.6 \pm 3.1$ & $0.9 \pm 1.4$ & $3.6 \pm 3.2$ \\
\hline
\end{tabular}

Table 4. Biomass fluxes of subplots in canopy gaps and in the closed canopy.

\begin{tabular}{lrrrrr}
\hline & \multicolumn{3}{c}{ Biomass growth $\left(\mathrm{kg} \mathrm{a}^{-1}\right)$} & \multicolumn{2}{c}{ Biomass mortality $\left(\mathrm{kg} \mathrm{a}^{-1}\right)$} \\
\cline { 2 - 6 } Position & Interval I & Interval II & Interval III & Interval II & Interval III \\
\hline Subplots in Gap 1 & $9.0 \pm 13.4$ & $8.4 \pm 12.1$ & $17.0 \pm 22.5$ & $5.8 \pm 9.8$ & $23.4 \pm 67.0$ \\
Subplots in Gap 2 & $3.3 \pm 5.0$ & $4.0 \pm 3.1$ & $8.1 \pm 6.6$ & $4.3 \pm 20.4$ & $17.6 \pm 32.0$ \\
Subplots in Gap 3 & $8.6 \pm 10.6$ & $5.0 \pm 5.6$ & $2.8 \pm 5.9$ & $1.2 \pm 3.4$ & $59.4 \pm 76.4$ \\
Subplots in closed canopy & $12.1 \pm 31.2$ & $9.0 \pm 19.7$ & $9.1 \pm 15.4$ & $3.4 \pm 29.9$ & $21.1 \pm 65.0$ \\
\hline
\end{tabular}
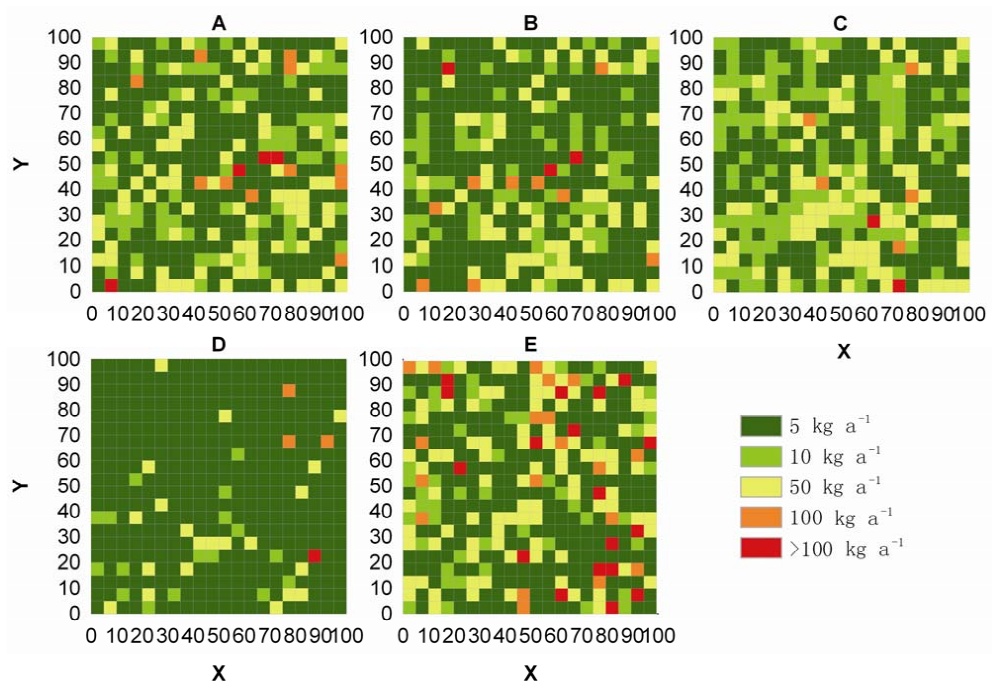

Fig. 9. Filled contour maps for biomass fluxes $\left(\mathrm{kg} \mathrm{a}^{-1}\right)$ of each subplot as indicated by (A) biomass growth in interval I, (B) biomass growth in interval II, (C) biomass growth in interval III, (D) biomass mortality in interval II and (E) biomass mortality in interval III.

\section{Discussion}

\subsection{Biomass, stem pools and fluxes of the community}

We observed similar fluctuations for stem and biomass pools, but the stem and biomass fluxes in the three periods fluctuated in different ways. During the three periods, when we carried out measurements, biomass growth was stable and biomass mortality showed a continuous decrease, while both the stem recruitment and stem mortality increased. The old-growth forest had stable stem recruitment and biomass growth. Results of stem fluxes were consistent with other previous observations (Sheil and May, 1996; Johnson et al., 2000; Davies, 2001).

Disturbances such as drought, hurricanes, insect outbreaks or wind (Beard et al., 2005; Mascaro et al., 2005), and physical conditions such as temperature, light and topography, are the two primary factors, which affect the temporal fluctuation of pools (Miura and Yamamoto, 2003; Lewis et al., 2004; Phillips et al., 2004). In this study, the fluctuation was affected by both disturbances and physical conditions. From 1992-1999, both biomass and stem fluxes were nearly 
balanced with the occurrences of insect outbreak and treefall. Such a balance reflected the dynamic equilibrium of biomass and stems. From 1999 to 2004, the balances of biomass and stems were broken by both an insect outbreak and the occurrence of a landslide, which caused remarkable increase of stem mortality and biomass mortality. However, there was increased stem recruitment, while biomass growth remained stable during disturbance.

\subsection{Comparisons of the stem recruitment and mortality to other studies}

Recruitment and mortality of stems with $\mathrm{DBH} \geq 2.5 \mathrm{~cm}$ in a 60 -yr-old tropical moist forest were $9 \%$ and $20 \%$ during a 10-yr period (Lang and Knight, 1983), which were both significantly lower than those during 1994-2004 in the plot presented here $(27 \%$ and $45 \%)$. Furthermore, the annual stem recruitment of $\mathrm{DBH} \geq 10 \mathrm{~cm}$ during the three intervals in the Dinghushan MAB Reserve were all within the range of the tropical forest in the Amazon (Table 5). However, the annual mortality of stems with $\mathrm{DBH} \geq 10 \mathrm{~cm}$ in interval III was higher than the maximum in the Amazon (Phillips et al., 2004).

Flux dynamics are an emergent property of under-lying forest structural, floristic and dynamic processes. Phillips et al. (2004) showed two extreme simplified situations: (i) a system driven entirely by catastrophic mortality, also known as exogenous disturbance events; or (ii) a system driven entirely by endogenous growth and recruitment processes, in which resource supply provides the ultimate driver for forest ecology so that trees die competing for these resources. On the one hand, from the comparisons of the stem mortality to other tropical forests, the former situation best approximated the reality in the plot. On the other hand, the stem recruitment was within the range of tropical forests, which showed the recovery response of old-growth forest to the disturbance in the fluctuation.

\subsection{The fluxes of indirect-influenced populations}

The biomass pool and stem pool in the indirect-influenced populations were divided into several sub-pools by species, DBH classes and subplots in space. Under such classifications, the variations of biomass and stem fluxes among subpools would be helpful to understand the contribution of different sub-pools on community fluxes and the relationship between the periods.

The populations with the average $\mathrm{DBH}<10 \mathrm{~cm}$ dominated the stem fluxes among the indirect-influenced populations. Furthermore, higher stem mortality rates were also found in the DBH classes of $1-10 \mathrm{~cm}$. This result in the sub-tropical forest is consistent with the results found in other tropical forests and boreal forests, where stem flux was commonly found in $\mathrm{DBH}<10 \mathrm{~cm}$ (Sheil and May, 1996; Lawson et al., 1999).
Table 5. The percent of stem mortality and stem recruitment of the monitoring standard of $\mathrm{DBH} \geq 10 \mathrm{~cm}$ in Dinghushan MAB Reserve.

\begin{tabular}{lrrr}
\hline & Interval I & Interval II & Interval III \\
\hline Stem mortality & $0.0 \%$ & $1.6 \%$ & $7.6 \%$ \\
Stem recruitment & $2.4 \%$ & $1.7 \%$ & $4.1 \%$ \\
\hline
\end{tabular}

The dominant populations in the biomass fluxes were composed of the populations in nearly all average DBH classes $(1.7 \pm 0.4 \mathrm{~cm}$ to $34.3 \pm 2.3 \mathrm{~cm})$. Furthermore, the biomass fluxes in different DBH classes were not significantly affected by the stem fluxes. There were different causes for biomass growth and mortality. The biomass growth was composed of two parts, namely, the increments of biomass of all surviving trees and that of the newly recruited trees. Although there was higher stem recruitment in DBH classes of $1-10 \mathrm{~cm}$, the surviving trees in bigger DBH classes still contributed more to the biomass growth. Thus, the distribution of biomass growth for DBH classes was not highly influenced by higher stem recruitment. As for mortality, the stem mortality of DBH classes $>10 \mathrm{~cm}$ is remarkably smaller than DBH classes of 1-10 cm (Sheil and May, 1996). However, the biomass storage of one dead tree increases with larger DBH. Accordingly, DBH classes $>10 \mathrm{~cm}$, which had smaller stem mortality, actually had larger biomass mortality.

Spatially, the subplots in the gaps showed significantly higher stem fluxes than those in closed canopy. Meanwhile the higher biomass accumulation rates were also found in the subplots of gaps after the gap formation. It suggests that stem fluxes were greater in gaps compared to those in non-gaps and growth rates of saplings were relatively high. This result was consistent with studies in tropical forests (Lang and Knight, 1983; Uhl et al., 1988; Hubbell et al., 1999; Battles and Fahey, 2000). Furthermore, there were also flux differences between gaps. Biomass and stem fluxes in Gap 1 were always greater than in Gap 2. This result was probably due to the different gap forming modes, for instance, tree-fall gaps formed high nutrient pools in surface soils from large masses of fresh litter from the fallen trees (Denslow et al., 1998).

\section{Conclusions}

The community fluctuation of the old-growth forest was influenced by a biotic factor and an abiotic factor. The old-growth forest had stable stem recruitment and biomass growth in the community fluctuation. The stem fluxes and biomass mortality of the community were significantly affected by disturbance, while the biomass growth appeared not to be greatly affected. Castanopsis chinensisi population functioned most importantly in the stability of biomass fluxes. Insect direct-influenced populations were seriously 
influenced by disturbance. The biomass and stem fluxes of indirect-influenced populations showed the spatial and temporal variations in dominant species, DBH classes and subplots. The gaps due to tree fall and landslides had remarkably higher stem fluxes than those in closed canopy. The biomass growth rate in gaps increased remarkably after the formation of the gaps. During the disturbances, the overall community function remained stable in the old-growth forest.

Acknowledgements. This work was funded by National Natural Science Foundation of China (Grants 40730102 and 30725006) and Natural Science Foundation of Guangdong Province, China (Grant 8351065005000001).

Edited by: T. Laurila

\section{References}

Battles, J. J. and Fahey, T. J.: Gap dynamics following forest decline: a case study of red spruce forests, Ecol. Appl., 10, 760$774,2000$.

Beard, K. H., Vogt, K. A., Vogt, D. J., Scatena, F. N., Covich, A. P., Sigurdardottrir, R., Siccama, T. G., and Crowl, T. A.: Structural and functional responses of a subtropical forest to 10 years of hurricanes and droughts, Ecol. Monogr., 75, 345-361, 2005.

Chapin III, F. S., Matson, P. A., and Mooney, H. A.: Principles of Terrestrial Ecosystem Ecology, 1st ed., Springer-Verlag, New York, 2002.

Davies, S. J.: Tree mortality and growth in 11 sympatric Macaranga species in Borneo, Ecology, 82, 920-932, 2001.

Denslow, J. S., Ellison, A. M., and Sanford, R. E.: Treefall gap size effects on above- and below-ground processes in a tropical wet forest, J. Ecol., 86, 597-609, 1998.

Elderd, B. and Doak, D. F.: Comparing the direct and communitymediated effects of disturbance on plant population dynamics: flooding, herbivory and Mimulus guttatus, J. Ecol., 94, 656-669, 2006.

Glenn-Lewin, D. C., Peet, R. K., and Veblen, T. T.: Plant Succession: Theory and Prediction, Chapman and Hall, London, 1992.

Guan, L., Zhou, G., Zhang, D., Liu, J., and Zhang, Q.: Twenty years of litter fall dynamics in subtropical evergreen broadleaved forests at the Dinghushan forest ecosystem research station, Acta Phytoecologica Sinica, 28, 449-456, 2004.

Huang, Z., Kong, G., and Wei, P.: Plant species diversity dynamics in Dinghu Mountain forests, Chinese Biodiversity, 6, 116-121, 1998 (in Chinese with English abstract).

Huang, Z. L.: The interactions of population dynamics of Thalassodes quadraria and the plant community structure and climate factors in Dinghushan, Chinese Journal of Ecology, 19, 24-27, 2000 (in Chinese with English abstract).

Hubbell, S. P., Foster, R. B., O’Brien, S. T., Harms, K. E., Condit, R., Wechsler, B., Wright, S. J., and de Lao, S. L.: Light-gap disturbances, recruitment limitation, and tree diversity in a neotropical forest, Science, 283, 554-557, 1999.

Johnson, C. M., Zarin, D. J., and Johnson, A. H.: Post-disturbance aboveground biomass accumulation in global secondary forests, Ecology, 81, 1395-1401, 2000.
Lang, G. E. and Knight, D. H.: Tree growth, mortality, recruitment, and canopy gap formation during a 10-year period in tropical moist forest, Ecology, 64, 1075-1080, 1983.

Lawson, D., Inouye, R. S., Huntly, N., and Carson, W. P.: Patterns of woody plant abundance, recruitment, mortality and growth in a 65 year chronosequence of old-fields, Plant. Ecol., 145, 267279, 1999.

Lewis, S. L., Phillips, O. L., Baker, T. R., Lloyd, J., Malhi, Y., Almeida, S., Higuchi, N., Laurance, W. F., Neill, D. A., Silva, J. N. M., Terborgh, J., Lezama, A. T., Vasquez Martinez, R., Brown, S., Chave, J., Kuebler, C., Nunes Vargas, P., and Vinceti, B.: Concerted changes in tropical forest structure and dynamics: evidence from 50 South American long-term plots, Philos. T. Roy. Soc. B., 359, 421-436, 2004.

Liang, X.: Study on gap habit changes and species ecophysiological responses in Dinghushan, China, Master's dissertation of South China institute of botany, Chinese Academy of Sciences, 2001 (in Chinese with English abstract).

Mascaro, J., Perfecto, I., Barros, O., Boucher, D. H., de la Cerda, I. G., Ruiz, J., and Vandermeer, J.: Aboveground biomass accumulation in a tropical wet forest in Nicaragua following a catastrophic hurricane disturbance, Biotropica, 37, 600-608, 2005.

Miura, M. and Yamamoto, S. I.: Effects of sprouting and canopy states on the structure and dynamics of a Castanopsis cuspidata var. sieboldii sapling population in an old-growth evergreen broad-leaved forest, Forest. Ecol. Manag., 183, 387-400, 2003.

Peng, L.: Changes in interspecific association of the climatic climax vegetation from 1984 to 2006 in Dinghushan, Guangdong, China, Acta Ecologica Sinica, 26, 3732-3739, 2006 (in Chinese with English abstract).

Peng, S., Huang, Z., Zhou, G., Zhou, X., Zhang, C., and He, W.: Gap formation characteristics and its effects on sapling composition and diversity in Dinghushan biosphere reserve, Journal of Tropical and Subtropical Botany, 11, 229-235, 2003 (in Chinese with English abstract).

Phillips, O. L., Baker, T. R., Arroyo, L., Higuchi, N., Killeen, T. J., Laurance, W. F., Lewis, S. L., Lloyd, J., Malhi, Y., Monteagudo, A., Neill, D. A., Nunez Vargas, P., Silva, J. N. M., Terborgh, J., Vasquez Martinez, R., Alexiades, M., Almeida, S., Brown, S., Chave, J., Comiskey, J. A., Czimczik, C. I., Di Fiore, A., Erwin, T., Kuebler, C., Laurance, S. G., Nascimento, H. E. M., Olivier, J., Palacios, W., Patino, S., Pitman, N. C. A., Quesada, C. A., Saldias, M., Torres Lezama, A., and Vinceti, B.: Pattern and process in Amazon tree turnover, 1976-2001, Philos. T. Roy. Soc. B., 359, 381-407, 2004.

Rydgren, K., Økland, R. H., and Hestmark, G.: Disturbance severity and community resilience in a boreal forest, Ecology, 85, 19061915, 2004.

Sheil, D. and May, R. M.: Mortality and recruitment rate evaluations in heterogeneous tropical forests, J. Ecol., 84, 91-100, 1996.

Shi, J., Huang, Z., Yi, W., Ouyang, X., and Zhou, X.: Dynamics of Erythrophleum Fordii community and conservation strategies, Journal of Northwest Forestry University, 20, 65-69, 2005 (in Chinese with English abstract).

Stephenson, N. L. and van Mantgem, P. J.: Forest turnover rates follow global and regional patterns of productivity, Ecol. Lett., 8, 524-531, 2005.

Tappeiner, J. C., Huffman, D., Marshall, D., Spies, T. A., and Bai- 
ley, J. D.: Density, ages, and growth rates in old-growth and young-growth forests in coastal Oregon, Can. J. Forest. Res., 27, 638-648, 1997.

Uhl, C., Clark, K., Dezzeo, N., and Maquirino, P.: Vegetation dynamics in Amazonian treefall gaps, Ecology, 69, 751-763, 1988.

Wen, D., Wei, P., Kong, G., Zhang, Q., and Huang, Z.: Biomass study of the community of Castanopsis chinensis+Schima superba+Cryptocarya concinna in a Southern China Reserve, Acta Ecologica Sinica, 17, 497-504, 1997 (in Chinese with English abstract).

Zhang, C., Huang, Z., Shi, J., Li, L., Wei, S., and Li, J.: Dynamics and causes of woody plant death in the monsoon evergreen broad-leaved forest in Dinghushan Nature Reserve, Acta Ecologica Sinica, 26, 2457-2462, 2006 (in Chinese with English abstract).
Zhou, G., Liu, S., Li, Z., Zhang, D., Tang, X., Zhou, C, Yan, J., and Mo, J.: Old-growth forests can accumulate carbon in soils, Science, 314, p. 1417, 2006.

Zhou, X., Huang, Z., Ouyang, X., Li, J., Guan, L., Xu, G., and Zhang, C.: Succession of the original Castanopsis chinensis Cryptocarya chinensis - Schima superba community of monsoom evergreen broad-leaved forest in Dinghushan Nature Reserve, Acta Ecologica Sinica, 25, 37-44, 2005 (in Chinese with English abstract). 